\title{
Herpesvírus Bovino Tipo 5 e Meningoencefalite Herpética Bovina ${ }^{1}$
}

\section{Meningoencephalitis by Herpesvirus Type 5}

\author{
Marlise Pompeo Claus ${ }^{2}$; Alice Fernandes Alfieri ${ }^{3}$; Amauri Alcindo Alfieri ${ }^{3 *}$
}

\section{Resumo}

\begin{abstract}
O herpesvírus bovino tipo 5 é um importante patógeno de bovinos jovens e adultos, e o agente etiológico da meningoencefalite herpética. A infecção, apesar da baixa morbidade, pode ocasionar taxa de letalidade próxima a 100\%. Devido às semelhanças com outras enfermidades que comprometem o sistema nervoso central de bovinos, em particular a raiva, o diagnóstico da doença clínica assume especial importância. Esta revisão tem por objetivo apresentar tópicos relacionados ao agente etiológico, à doença e aos métodos de diagnóstico e de profilaxia da meningoencefalite herpética bovina.

Palavras-chave: Bovinos; Sistema Nervoso Central; Herpesvírus Bovino Tipo 5; Meningoencefalite Herpética
\end{abstract}

\begin{abstract}
Bovine herpesvirus type 5 is an important pathogen in young and adult cattle and causes meningoencephalitis. The infection, although it causes low morbidity, can cause a lethality rate close to $100 \%$. Diagnosis of the clinical disease is very important due to the similarities with other diseases that affect the cattle central nervous system, especially rabies. This revision aims to present topics related to the etiological agent, the disease, diagnosis and prophylaxis methods of bovine herpetic meningoencephalitis.
\end{abstract}

Key words: Cattle; Central Nervous System; Meningoencephalitis; Bovine Herpesvirus Type 5

\section{Introdução}

A meningoencefalite herpética bovina é uma infecção viral do sistema nervoso central (SNC), causada pelo herpesvírus bovino tipo 5 (BHV-5), que acomete animais de todas as faixas etárias, porém, principalmente animais jovens (STUDDERT,1989). A infecção, geralmente fatal, é caracterizada por uma meningoencefalite não purulenta, associada a lesões necróticas do córtex cerebral e inflamatórias nas substâncias branca e cinzenta (CARRILO et al.,1983; RIET-CORRÊA et al.,1989).

\section{Etiologia}

O BHV-5, ainda sem gênero definido, está classificado na família Herpesviridae, sub-família Alphaherpesvirinae, que agrupa inúmeras espécies virais que podem infectar uma gama de hospedeiros

\footnotetext{
1 Apoio Financeiro: CNPq, CAPES e CPG/UEL.

2 Aluna do Programa de Pós-graduação em Ciência Animal (área de concentração: Sanidade Animal; nível: Mestrado), Universidade Estadual de Londrina (UEL).

3 Laboratório de Virologia Animal, DMVP, CCA, UEL, Londrina, Paraná, Brasil. Caixa Postal: 6001. Tel.: 43 33714068. E-mail: alfieri@uel.br.

* Autor para correspondência.
} 
(ROIZMAN et al., 1992). Os herpesvírus são heterogêneos, não diferenciados morfologicamente pela microscopia eletrônica e podem replicar-se em diferentes tecidos como o nervoso, glandular, linfóide e em órgãos parenquimatosos (STRAUB, 1982). Além do BHV-5, outro herpesvírus de grande importância clínica, epidemiológica e econômica para a pecuária bovina é o herpesvírus bovino tipo 1 (BHV-1), agente etiológico de duas entidades clínicas com ampla distribuição, denominadas rinotraqueíte infecciosa bovina (IBR) e vulvovaginite/balanopostite pustular infecciosa (IPV) (GIBBS; RWEYEMANN, 1977).

Os herpesvírus agrupados na sub-família Alphaherpesvirinae apresentam como características gerais o diâmetro de aproximadamente 70 a 110 nm, genoma DNA linear de fita dupla com aproximadamente 137 kilobases $(\mathrm{Kb})$ constituído por uma região única longa (UL) e outra única curta (US); nucleocapsídeo icosaédrico com 162 capsômeros e envelope glicoprotéico (FENNER, et al.,1993; WIRTH, 1993).

A replicação viral ocorre no núcleo celular. A maturação envolve a encapsidação do DNA no interior do nucleocapsídeo, seguida pela aquisição do envelope durante o processo de brotamento. A produção da progênie viral infecciosa é acompanhada pela lise da célula infectada (ROIZMAN et al., 1992; FENNER et al.,1993).

Os herpesvírus codificam várias enzimas envolvidas no metabolismo do ácido nucléico como a timidina kinase (TK), timidina sintetase, dUTPase e ribonucleotídeo redutase, além daquelas que participam da síntese do DNA como a DNA polimerase a helicase e a primase (ROIZMAN et al., 1992).

Atualmente são descritas 10 glicoproteínas do envelope viral, denominadas $\mathrm{gB}, \mathrm{gC}, \mathrm{gD}, \mathrm{gE}, \mathrm{gG}$, gH, gI, gK, gL, e gM. Estas glicoproteínas possuem diferentes propriedades antigênicas, funções na replicação viral e interações com a célula infectada (SCHWYZER; ACKERMANN,1996). As glicoproteínas gB, gC e gD são importantes componentes imunogênicos e estão envolvidas nas interações iniciais com a célula hospedeira. A gC é considerada a mais imunogênica e está relacionada à adsorção, enquanto a gB e a gD estão envolvidas na penetração e fusão da partícula viral às células alvo (BABIUK et al.; 1996).

Os alphaherpesvírus, incluindo o herpesvírus simplex humano 1 e 2 (HSV-1, HSV-2), o vírus da pseudoraiva ou vírus da Doença de Aujeszky e o BHV1, contêm glicoproteínas funcionais e estruturais homólogas, destacando-se as três principais glicoproteínas (gB, gC e gD) (CHOWDHURY, 1995).

O gene da gB localiza-se na região UL do genoma e codifica um poliptídeo de 932 aminoácidos. A gB é inicialmente sintetizada com $117 \mathrm{Kda} e$, com a ligação a oligossacarídeos, forma um produto de $130 \mathrm{Kda}$. Muitas dessas formas maduras são clivadas para formar um polipeptídeo de 74 Kda e outro de $55 \mathrm{Kda}$ (VAN DRUNEN LITTEL-VAN DER HURK et al., 1990).

A gC está presente no envoltório do virion e na membrana da célula infectada. $\mathrm{O}$ gene da gC codifica uma proteína de 521 aminoácidos que apresenta quatro sítios potenciais de ligação a oligossacarídeos. A gC é sintetizada com $69 \mathrm{Kda}$, como um precursor parcialmente glicosilado, que precede a formação de um produto maduro de $91 \mathrm{Kda}$. Ela é considerada a mais importante glicoproteína envolvida na adsorção do vírus à célula e, em cultivo celular, liga-se aos receptores de heparina (LIANG et al., 1992).

O gene da gD está localizado na região US e codifica um polipeptídeo de 147 aminoácidos com três sítios potenciais para a adição de oligossacarídeos. A gD é sintetizada como um precursor de $63 \mathrm{Kda}$, parcialmente glicosilado, que conduz à formação de proteínas maduras de $71 \mathrm{Kda}$ (FEHLER et al., 1992).

Uma das características epidemiológicas mais importantes da família Herpesviridae é a capacidade de estabelecer latência em células ganglionares do animal infectado. Nesta situação, podem ocorrer episódios de reexcreção viral não acompanhados de sinais clínicos. Por meio de pontes intercelulares os herpesvírus podem migrar de uma célula à outra sem entrar em contato com o espaço extracelular e com 
os líquidos corporais, ficando indisponíveis para a atuação de anticorpos. Novos episódios de eliminação viral podem ocorrer em resposta à administração de corticóides, ou mesmo em situações estressantes (HOMAN; EASTERDAY, 1983; ACKERMANN; WYLER, 1984; STRAUB, 1990; ROCK, 1993; BELKNAP et al.,1994).

Durante o período de latência não é possível o isolamento do vírus e tão pouco a demonstração de antígenos virais na célula infectada. Entretanto, a utilização de técnicas moleculares como a hibridização in situ e a reação em cadeia pela polimerase (PCR) são capazes de detectar o DNA viral e identificar os sítios de latência, como o tecido trigeminal para o BHV-5 e linfonodos e mucosa nasal para o BHV-1. Em contraste com a infecção ativa, onde a replicação viral seguida de lise celular ocorre principalmente em tecidos periféricos, a infecção latente geralmente não determina a lise da célula infectada e ocorre em células de vida longa, com baixa taxa de replicação e altamente diferenciadas, como os neurônios e células linfóides (ASHBAUGH et al., 1997; ENGELS; ACKERMANN, 1996; CARON et al., 2002).

Para explicar o surgimento e a adaptação do BHV5 à espécie bovina foram formuladas várias hipóteses, ainda sem confirmação. O BHV-5 poderia ser um herpesvírus natural de espécies de ruminantes relacionadas que teria se adaptado aos bovinos. Nestes animais, por uma falha em fases finais do ciclo de replicação viral, por ocasião do estabelecimento de latência no gânglio trigêmeo, o vírus provocaria uma encefalite fatal. Outras hipóteses são que o BHV-5 poderia ser um vírus recombinante entre o BHV-1 e outro herpesvírus relacionado de ruminantes ou então um rearranjo genômico do BHV-1 (STUDDERT, 1989).

Os primeiros isolamentos de herpesvírus a partir de animais com sinais clínicos neurológicos, por carência de metodologia para a caracterização viral, foram atribuídos ao BHV-1. Porém, estudos preliminares já apontavam diferenças entre os herpesvírus isolados de focos de encefalite, daqueles isolados de focos de problemas respiratórios e/ou genitais (METZLER et al., 1986; RIET-CORRÊA et al., 1989; COLLINS et al., 1993; D'OFFAY et al.,1993).

Devido às semelhanças com estirpes virais respiratórias e genitais, inicialmente o BHV-5 foi classificado como BHV-1.3. Posteriormente, com base em diferenças epidemiológicas, antigênicas e moleculares, houve a proposta de reclassificação, na qual o BHV-5 passou a compor uma nova espécie da família Herpesviridae. Entretanto, a maior diferença entre o BHV-1 e o BHV-5 está na capacidade do BHV-5 invadir e replicar-se no SNC, determinando enfermidade neurológica (BAGUST; CLARK, 1972; STUDDERT, 1989; ROIZMAN et al.,1992; BELKNAP et al., 1994).

Com relação à composição genômica, o DNA do BHV-5 apresenta similaridade de $85 \%$ com o BHV1. Sugere-se que as diferenças na seqüência de nucleotídeos entre esses dois vírus estejam distribuídas por todo o genoma (ENGLES et al.,1987; CHOWDHURY, 1995).

Análises com anticorpos monoclonais (MAbs) têm demonstrado diferenças antigênicas entre as principais glicoproteínas (gB, gC e gD) do BHV-5 e do $\mathrm{BHV}-1$. A seqüência de aminoácidos do segmento amino-terminal da $\mathrm{gC}$ desses dois vírus apresenta diferenças significativas (COLLINS et al., 1993; CHOWDHURY, 1995; ROEHE et al., 1997).

Os estudos conduzidos com o objetivo de elucidar as bases genômica e antigênica da neurovirulência do BHV-5 têm-se concentrado nas glicoproteínas virais que apresentam as maiores diferenças quando comparadas às presentes em estirpes do BHV-1. Assim, glicoproteínas como a gC, gE e gI têm sido relacionadas com o potencial neuropatogênico do BHV-5 (CHOWDHURY et al., 2000a, 2000b; ALMUBARAK et al., 2001). 


\section{Epidemiologia}

A diferenciação sorológica entre o BHV-1 e o BHV-5 é de difícil realização devido à ocorrência de extensas reações cruzadas que não permitem o estabelecimento da proporção de animais supostamente infectados com o BHV-1, que na verdade foram infectados com o BHV-5. Dessa forma é desconhecida a prevalência do BHV-5 no mundo (ROEHE et al., 1997, 1998). Porém, surtos de encefalite herpética têm sido relatados em vários países como Austrália, Hungria, Estados Unidos, Canadá e Argentina (FRENCH, 1962; BARTHA et al., 1969; EUGSTER et al., 1974; GOUGH; JAMES, 1975; CARRILLO et al., 1983).

No Brasil já foram descritos casos clínicos ocorridos nos Estados do Rio Grande do Sul, Mato Grosso, Mato Grosso do Sul, São Paulo, Paraná, Rio de Janeiro e Minas Gerais. Embora não existam relatos da infecção em outros Estados, sugere-se que o BHV5 seja enzoótico em todo o país (RIET-CORRÊA et al.,1989; ROEHE et al., 1997; SALVADOR et al., 1998; CLAUS et al., 2000; COLODEL et al., 2002; GOMES et al., 2002; SOUZA et al., 2002).

\section{Patogenia}

A patogenia da infecção pelo BHV-5 tem sido estudada por meio de infecção experimental em coelhos, cordeiros e terneiros (BAGUST; CLARK, 1972; BELKNAP et al., 1994; CHOWDHURY et al.,1997; SILVA et al., 1998; BELTRÃO et al., 2000; CARON et al., 2002).

Em coelhos, a inoculação intranasal da estirpe americana TX89 do BHV-5, associada ao tratamento com dexametasona, resultou em $100 \%$ de morbidade e $70 \%$ de mortalidade devido à meningoencefalite. $\mathrm{O}$ vírus foi isolado do bulbo olfatório, córtex anterior e posterior, amígdalas e hipocampos, e com menor frequiência a partir do diencéfalo, ponte e medula, do cerebelo e do gânglio trigêmeo. Achados patológicos no cérebro incluíram degeneração neuronal, gliose e manguito perivascular predominantemente no córtex olfatório, amígdala e hipocampo. Estes achados sugerem que após a inoculação intranasal, o BHV-5 propaga-se para o SNC pelos tratos olfatório e trigeminal, sendo que o primeiro favorece o aparecimento dos efeitos neuropatogênicos. Coelhos inoculados com a estirpe Cooper do BHV-1 não desenvolveram sinais neurológicos e o vírus não foi recuperado do cérebro (CHOWDHURY et al., 1997).

A infecção experimental com o BHV-5 em ovinos foi capaz de reproduzir vários aspectos da infecção em bovinos. Os animais inoculados pela via intranasal excretaram e transmitiram o vírus para os animais em contato. Sinais clínicos de encefalite foram evidenciados 10 dias pós-inoculação e o tratamento com dexametasona provocou reativação da infecção latente e reexcreção viral. Os resultados demonstraram que os ovinos são suceptíveis à infecção aguda e latente pelo BHV-5 e sugerem o potencial da ocorrência de infecções naturais em ovinos pelo BHV-5 (SILVA et al., 1998).

A inoculação em bezerros neonatos, privados de colostro, com isolados americanos do BHV-5, resultou em encefalite fatal com sinais clínicos observados 9 a 10 dias após a inoculação. As lesões histológicas no cérebro consistiram de meningoencefalite difusa não supurativa, caracterizada por necrose neuronal, gliose e manguito perivascular linfocitário. Em contraste, os animais inoculados com o BHV-1 não apresentaram lesões cerebrais, e pouco ou nenhum vírus foi recuperado dos tecidos nervosos. Por outro lado, os neonatos que receberam colostro demonstraram proteção contra o BHV-5, evidenciando a eficiência da imunidade passiva. Anticorpos colostrais induzidos pelo BHV-1.1 podem ter sido responsáveis por essa proteção (BELKNAP et al., 1994).

\section{Sinais Clínicos}

A infecção pelo BHV-5 em bovinos determina um quadro neurológico que inclui diversos sinais clínicos, que podem ou não estar associados à 
anorexia. Entre os sinais mais freqüentes destacamse corrimento nasal e ocular, tremores musculares, andar em círculos, incoordenação, opistótono, nistagmo, bruxismo e convulsões. Em um mesmo foco de meningoencefalite herpética, não necessariamente, os animais acometidos irão apresentar os mesmos sinais clínicos. A faixa etária acometida é ampla, podendo comprometer desde bezerros com menos de um mês de idade até animais com idade superior a três anos (FRENCH, 1962; BAGUST; CLARK, 1972; SCHUDEL et al., 1986; RIETCORRÊA et al., 1989; VASCONCELOS et al.,1993).

\section{Achados Patológicos}

Em trabalho realizado por Salvador et al. (1998), relatando focos de encefalite bovina pelo BHV-5, não foram observadas alterações macroscópicas significativas em grande parte dos cérebros examinados. Em alguns casos pôde-se constatar malácia no córtex cerebral, bem como achatamento das circunvoluções, protrusão do cerebelo através do foramen magno e pontos hemorrágicos no córtex cerebral. Histologicamente evidenciou-se intensa meningite não supurativa difusa, com manguitos perivasculares de células mononucleares presentes tanto na substância branca quanto na cinzenta. Apenas a substância branca no cerebelo foi afetada, não sendo encontradas alterações no córtex. Outros achados incluíram necrose neuronal maciça, atingindo grandes extensões do córtex com presença de neurônios acentuadamente eosinofílicos, retraídos e com aumento do espaço perineuronal. A malácia esteve presente nos casos onde a evolução foi igual ou superior a três dias. Foram observados corpúsculos de inclusão intranucleares em neurônios e, com maior freqüência, em astrócitos. A maior parte dos corpúsculos eram eosinofílicos e apresentavam-se ao centro do núcleo, circundados por um alo claro com a cromatina deslocada para a periferia. Eventualmente, observaram-se corpúsculos basofílicos que ocupavam todo o núcleo que apresentava-se aumentado. A presença de corpúsculos também é relatada por Colodel et al. (2002).
Em um foco de BHV-5 ocorrido no Rio Grande do Sul, 12 bezerros de aproximadamente um mês de idade foram afetados, sendo que nove vieram a óbito. À necropsia foram observados pneumonia, exsudato purulento nos brônquios, exsudato fibrino-purulento no pericárdio e lesões no rúmen e abomaso. Histologicamente, a área de maior importância foi o SNC, que apresentou lesões caracterizadas por meningoencefalite, necrose do córtex e gliose. Evidenciou-se acúmulo perivascular de linfócitos, macrófagos, plasmócitos e, em algumas ocasiões, neutrófilos. Em todos os casos foram observadas áreas de necrose do córtex cerebral, presença de macrófagos e acúmulo de células inflamatórias nas áreas da substância cinzenta (RIET-CORRÊA et al., 1989).

\section{Diagnóstico}

\section{Diagnóstico clínico}

O diagnóstico clínico da infecção pelo BHV-5 pode ser inconclusivo devido à variedade de sinais clínicos. Alterações neurológicas freqüentemente relatadas nos casos de encefalite herpética podem também ocorrer em outras enfermidades.

$\mathrm{Na}$ forma sistêmica da doença podem ser encontradas lesões em outros órgãos além do cérebro, como rúmen e abomaso. Também são relatadas formas nervosas com comprometimento do sistema digestório e/ou respiratório. A pneumonia aspirativa pode ocorrer como conseqüência de desordens neurológicas (REED et al., 1973; WATT et al.,1981; SMITH, 1996).

No diagnóstico clínico da meningoencefalite herpética, as taxas de morbidade (0,05 a 5\%) e letalidade (próximas de $100 \%$ ), podem direcionar o diagnóstico, bem como excluir outras enfermidades. Taxas de morbidade que variaram de $0,13 \%$ a $13,3 \%$ e letalidade de $100 \%$, foram observadas em um surto de BHV-5 que comprometeu 12 rebanhos bovinos no Estado do Mato Grosso ((SALVADOR et al., 1998; COLODEL et al., 2002). 


\section{Diagnóstico Laboratorial}

A sorologia tem valor limitado no diagnóstico indireto, uma vez que os métodos rotineiros disponíveis para a detecção de anticorpos não diferenciam animais infectados pelo BHV-5 daqueles infectados pelo BHV-1.

Em estudo realizado para a tentativa de avaliação sorológica discriminativa entre animais infectados com o BHV-1 e o BHV-5, testes de soroneutralização foram empregados frente a estirpes de ambos os tipos virais e os títulos obtidos foram comparados. Os resultados demonstraram, além da reatividade sorológica entre esses vírus, uma proporção de animais suspeitos de infecções pelo BHV1 que foram de fato infectados pelo BHV-5 (TEIXEIRA et al., 1997).

O diagnóstico laboratorial direto, pela detecção do agente etiológico, envolve o isolamento do BHV5 em cultivo celular e a microscopia eletrônica. $\mathrm{O}$ isolamento viral pode ser realizado em células MDBK (Madin Darby bovine kidney), cultivos primários de células de testículo de terneiro (TT), de pulmão de feto bovino e de células turbinadas de bovino (BT) (RIET-CORRÊA et al., 1989; BELKNAP et al., 1994; SALVADOR et al., 1998).

Para a detecção de componentes virais, como proteínas, podem ser empregar técnicas de imunofluorescência e imunoperoxidase. Amostras submetidas a baterias de MAbs apresentaram resultados distintos no teste de imunofluorescência. A estirpe Jura do BHV-1 reagiu com os 43 MAbs produzidos com a estirpe LA de BHV-1. As estirpes argentina A663 e a australiana N569 do BHV-5 reagiram somente com 19 desses mesmos MAbs (METZLER et al., 1986).

Em estudo comparativo com o método de hibridização, a técnica de imunoperoxidase mostrouse eficaz na detecção de proteínas virais. Não foram verificados resultados falso-negativos e a imunoperoxidase demonstrou maior sensibilidade que os métodos convencionais, como o isolamento viral (GIAVEDONI et al., 1988).
Técnicas de biologia molecular, para a detecção do genoma viral, como a PCR e a hibridização, podem ser empregadas com sucesso para o diagnóstico da infecção pelo BHV-5 (GIAVEDONI et al., 1988). Ros et al. (1999) desenvolveram um sistema de semi-nested PCR para a gC, detectando simultaneamente o BHV-1 e o BHV-5. Trabalho semelhante foi realizado por Claus (2002), que também tendo como alvo seqüências específicas da gC, desenvolveu e avaliou um método de Multiplex-PCR para a detecção simultânea, e em apenas uma reação, do BHV-1 e do BHV-5. A técnica de PCR pode ainda ser utilizada em amostras de tecidos e swabs de secreções respiratórias e vaginais para a identificação dos sítios de latência do BHV-5 e do BHV-1 (ASHBAUGH et al., 1997).

\section{Diagnóstico Diferencial}

Os sinais neurológicos presentes na infecção pelo BHV-5 podem ser observados em diversas situações onde haja comprometimento das funções do SNC. Dessa forma, é fundamental proceder o diagnóstico diferencial. $\mathrm{Na}$ anamnese poderão ser obtidas algumas informações que podem, em parte, direcionar o diagnóstico como: taxas de morbidade e de letalidade; tipo de alimentação (silagem); presença de plantas tóxicas ou pastagens próximas a lavouras; histórico de vacinação contra clostridioses, raiva e IBR; evolução da doença clínica e outros sinais intercorrentes. À necrópsia, a presença e/ou ausência de lesões macroscópicas no SNC e em outros órgãos também é relevante na elaboração de um diagnóstico.

Algumas doenças infecciosas como a raiva, a leucose enzoótica bovina, a listeriose, a enterotoxemia, a forma cerebral da babesiose e mesmo a encefalopatia espongiforme bovina, além de doenças de etiologia múltipla como a poliencefalomalácia (PEM) devem ser incluídas em um diagnóstico diferencial.

A raiva é uma das principais enfermidades a ser considerada na presença de sinais clínicos neurológicos em bovinos devido ao seu caráter zoonótico. 
A epidemiologia e a manifestação clínica da raiva e da meningoencefalite herpética são muito semelhantes, porém a raiva dos herbívoros está associada a regiões endêmicas e à presença de morcegos hematófagos.

Os sinais clínicos na raiva bovina são caracterizados por ataxia, andar cambaleante, principalmente dos membros posteriores, flacidez da cauda, tenesmo retal, atonia anal, salivação excessiva, afonia, hiperestesia e déficit na propriocepção. As lesões histológicas localizam-se, principalmente, no encéfalo e o diagnóstico é realizado pela técnica de imunofluorescência direta e pela inoculação em camundongos (FENNER et al., 1993; SMITH, 1996).

A meningoencefalite herpética e a PEM são duas enfermidades do SNC de bovinos onde a similaridade dos sinais clínicos e das lesões pode induzir a erros tanto no diagnóstico clínico quanto no histopatológico.

A PEM é caracterizada pelo amolecimento ou necrose da substância cinzenta do cérebro que ocasiona sinais clínicos caracterizados por decúbito, cegueira aparente, opistótono, andar cambaleante, movimentos de pedalagem, anorexia e depressão, rigidez dos membros, tremor muscular e salivação excessiva. A enfermidade, de etiologia múltipla, está relacionada à deficiência de tiamina, em associação com outros fatores como o excesso de grãos na ração, ao alto consumo de enxofre, proveniente da alimentação, e a alterações no manejo como privação de água e alimentos, além de condições estressantes como o transporte e inversões climáticas repentinas (JUBB; HUXTABLE, 1993; RADOSTITS et al.,1994; NAKAZATO et al., 2000).

Nakazato et al. (1998) conduziram um estudo com o objetivo de evidenciar alterações que pudessem auxiliar no diagnóstico diferencial entre a meningoencefalite herpética e a PEM. As alterações mais características em cada enfermidade foram: i) necrose neuronal de todas as camadas da córtex cerebral encontrada na infecção pelo BHV-5 e ausente na PEM; ii) infiltrado inflamatório constituído prin- cipalmente por células mononucleares (linfócitos e monócitos) em substância branca e cinzenta, meninges e ao redor de vasos sangüíneos presente nos casos de meningoencefalite herpética e ausentes nos casos de PEM; iii) corpúsculos de inclusão intranucleares eosinofílicos em astrócitos foram encontrados na maioria dos casos de infecção pelo BHV-5 e em nenhum dos casos de PEM.

\section{Profilaxia}

Devido às similaridades em aspectos biológicos e moleculares entre o BHV-5 e o BHV-1, ocorrem significativas reações sorológicas entre os dois vírus. Dessa forma, a mesma tecnologia utilizada para a produção de vacinas contra o BHV-1, é apontada como alternativa para o controle dos surtos de meningoencefalite pelo BHV-5 (FENNER et al., 1993; ROMERA et al., 1998; HALFEN et al., 2000).

Nas infecções por herpesvírus, a resposta imunológica do tipo humoral impede a ligação e a entrada do vírus na célula alvo, sendo os anticorpos responsáveis pela neutralização viral. No processo de reativação viral, é de grande importância a imunidade celular citotóxica, onde as células infectadas são destruídas, prevenindo assim o transporte viral e a sua eliminação para o meio ambiente e animais suscetíveis. O controle da infecção pelo herpesvírus, como o BHV-1, fundamenta-se principalmente na imunização com vacinas inativadas ou com vacinas vivas modificadas. Na indisponibilidade, até o momento, de um imunógeno contendo especificamente o BHV-5, as vacinas preparadas com o BHV-1 podem ser utilizadas, de uma forma emergencial, para a tentativa de controle de focos de meningoencefalite herpética (STRAUB, 1991; FENNER et al., 1993).

$\mathrm{Na}$ avaliação da capacidade imunogênica do BHV-5, foram utilizadas quatro vacinas inativadas, produzidas com uma amostra de BHV-5 isolada de um surto de meningoencefalite no Estado do Rio Grande do Sul. Duas vacinas foram elaboradas com adjuvante oleoso e duas com hidróxido de alumínio. As quatro vacinas testadas foram consideradas se- 
guras, pois nenhum animal vacinado demonstrou reações localizadas ou sistêmicas. Entretanto, após receberem três doses da vacina com intervalos de 30 dias, somente os animais vacinados com formulações contendo adjuvante oleoso desenvolveram resposta sorológica significativa (HALFEN et al., 2000).

Em infecção experimental de bezerros neonatos foi demonstrada a proteção cruzada entre o BHV-1 e o BHV-5. O estudo compreendeu animais que receberam ou não colostro, inoculados pela via intranasal com aerossóis contendo o BHV-5. O colostro era proveniente de vacas vacinadas rotineiramente com vacina viva modificada contra o BHV-1.1. Sete dias pósinoculação, os animais privados de colostro apresentaram anorexia, descarga nasal serosa que progrediu para mucopurulenta e sinais neurológicos que tiveram início nove dias pós-inoculação. Nos bezerros que receberam colostro ao nascimento e $12 \mathrm{~h}$ após, embora tenham se tornado infectados, não foi evidenciada a enfermidade neurológica. O BHV-5 foi reativado da forma latente em um desses animais após a administração de dexametasona 60 dias pós-inoculação. Os autores concluíram que os anticorpos colostrais dirigidos contra o BHV-1.1 podem ter sido responsáveis por essa proteção (BELKNAP et al., 1994).

Dessa forma, embora ainda não existam comercialmente vacinas específicas para o $\mathrm{BHV}-5$, acreditase que os animais vacinados com o BHV-1 possuam também alguma imunidade cruzada para o BHV-5.

\section{Conclusão}

Devido à importância da infecção de bovinos pelo BHV-5 é fundamental que testes sorológicos, capazes de discriminar a resposta imunológica induzida pelo BHV-1 e pelo BHV-5, sejam desenvolvidos e utilizados rotineiramente. Com isto, poderá ser esclarecida a epidemiologia da infecção pelo BHV5. Da mesma forma, o desenvolvimento de técnicas visando o diagnóstico etiológico do BHV-5 também é de fundamental importância para a diferenciação de outras enfermidades do SNC que acometem os bovinos. Os recentes avanços no campo da biologia molecular podem ser importantes ferramentas para a obtenção de um diagnóstico etiológico rápido e preciso. Os estudos direcionados para a identificação das proteínas virais envolvidas na capacidade do vírus invadir o SNC e causar doença neurológica devem auxiliar no entendimento da neuropatogenicidade do BHV-5. O estabelecimento da importância econômica da infecção determinada pelo BHV-5 deve levar ao desenvolvimento de vacinas que possam ser utilizadas de forma segura no controle e profilaxia dessa virose.

\section{Referências}

ACKERMANN, M.; WYLER, R. The DNA of an IPV strain of bovine herpesvirus 1 in sacral ganglia during latency after intravaginal infection. Veterinary Microbiology, v.9, p.53-63, 1984.

AL-MUBARAK, A. et al. Role of gE/gI in BHV-5 neuropathogenesis. In: INTERNATIONAL HERPESVIRUS WORKSHOP, 26., 2001, Regensburg. Proceedings... Regensburg, 2001.

ASHBAUGH, S.E. et al. Specific detection of shedding and latency of bovine herpesvirus 1 and 5 using a nested polymerase chain reaction. Journal of Veterinary Diagnostic investigation, v.9, n.4, p.387-394, 1997.

BABIUK, L.A.; van DRUNEN, H.L.; TIKOO, S.K. Immunology of bovine herpesvirus 1 infection. Veterinary Microbiology, v.53, n.1-2, p.31-42, 1996.

BAGUST, T.J.; CLARK L. Pathogenesis of meningoencephalitis produced in calves by infectious bovine rhinotracheitis herpesvirus. Journal of Comparative Pathology, v.82, p.375-383, 1972.

BARTHA, A. et al. Occurrence of encephalomyelitis caused by infectious bovine rhinotracheitis in calves in Hungary. Acta Veterinary Academiae Scientiarum Hungaricae, v.19, p.145-151, 1969.

BELKNAP, E.B. et al. Experimental infection of neonatal calves with neurovirulent bovine herpesvirus type 5 (BHV-5). Veterinary Pathology, v.31, p.358-365, 1994.

BELTRÃO, N. et al. Infecção e enfermidade neurológica pelo herpesvírus bovino tipo 5 (BHV-5): coelhos como modelo experimental. Pesquisa Veterinária Brasileira, v.20, n.4, p.144-150, 2000. 
CARON, L. et al. Latent infection by bovine herpesvirus type-5 in experimentally infected rabbits: virus reactivation, shedding and recrudescence of neurological disease. Veterinary Microbiology, v.84, n.4, p.285-295, 2002.

CARRILO, B.J. et al. Meningoencephalitis caused by IBR virus in calves in Argentina. Zentralblatt für Veterinärmedizin Reihe B, v.30, p.327-332, 1983.

CHOWDHURY, S.I. Molecular basis of antigenic variation between the glycoproteins $\mathrm{C}$ of respiratory bovine herpesvirus 1 (BHV-1) and neurovirulent BHV5. Virology, v.213, p.558-568, 1995.

CHOWDHURY, S.I. et al. Neuropathology of bovine herpesvirus type 5 (BHV-5) meningoencephalitis in a rabbit seizure model. Journal of Comparative Pathology, v. 117, p. 295-310, 1997.

CHOWDHURY, S.I. et al. Neurovirulence of glycoprotein $\mathrm{C}(\mathrm{gC})$ deleted bovine herpesvirus type 5 (BHV-5) and BHV-5 expressing BHV-1 gC in the rabbit seizure model. Journal of Neurovirology, v.6, n.4, p.284295, 2000a.

CHOWDHURY, S.I. et al. Bovine herpesvirus 5 glycoprotein $\mathrm{E}$ is important for neuroinvasiveness and neurovirulence in the olfactory pathway of the rabbit. Journal of Virology, v.74, n.5, p.2094-2106, 2000b.

CLAUS, M.P. Detecção do herpesvírus bovino tipos $1 e$ 5 por amplificação parcial do gene da glicoproteína $C e$ estudo retrospectivo da meningoencefalite herpética bovina. 2002 94f. Dissertação (Mestrado em Sanidade Animal) - Centro de Ciências Agrárias, Universidade Estadual de Londrina, Londrina.

CLAUS, M.P et al. Isolation and partial characterization of bovine herpesvirus in cattle whith neurological signs. Virus Reviews \& Research, v.5, n.2, p.120, 2000.

COLLINS, J. K. et al. Antigenic differences between the major glycoproteins of bovine herpesvirus type 1.3. Journal of General Virology, v.74, p.1509-1517, 1993.

COLODEL, E.M. et al. Meningoencefalite necrosante causada por herpesvírus bovino no Estado de Mato Grosso, Brasil. Ciência Rural, v.32, n.2, p.293-298, 2002.

D'OFFAY, J.M.; MOCK, R.E.; FULTON, R.W. Isolation and characterization of encephalitic bovine herpesvirus type 1 isolates from cattle in North America. American Journal Veterinary Research, v.54, n.4, p.534-539, 1993.

ENGLES, M.; ACKERMANN, M. Pathogenesis of ruminant herpesvirus infections. Veterinary Microbiology, v. 53, n. 1, p. 3-15, 1996.

ENGLES, M. et al. The genome of bovine herpesvirus 1 (BHV-1) exhibiting a neuropathogenic potential compared to known BHV-1 strains by restriction site mapping and cross-hybridization. Virus Research, v.6, p.57-73, 1987.

EUGSTER, A.K.; ANGULO, A.A.; JONES, L.P. Herpesvirus encephalitis in range calves. In: ANNUAL MEETING OF THE AMERICAN ASSOCIATION OF VETERINARY LABORATORY DIAGNOSTICIANS, 17., 1974, Virginia. Proceedings... Virginia, 1974. v.17, p.267-290.

FEHLER, F. et al. Glycoprotein IV of bovine herpesvirus 1- expressing cell line complements and rescues a conditionally lethal viral mutant. Journal Virology, v.66, n.2, p.831-839, 1992.

FENNER, F. et al. Veterinary Virology. 2.ed. London: Academic Press, 1993.

FRENCH, E.L. A specific virus encephalitis in calves: isolation and characterization of the causal agent. Australian Veterinary Journal, v.38, p.216-221, 1962.

GIAVEDONI, L.D. et al. Rapid diagnosis of bovine herpesvirus encephalitis: comparasion of nucleic acid hybridization and immunoperoxidase methods using clinical samples. Journal of Veterinary Medicine, v.35, p.280-285, 1988.

GIBBS, E.P.J.; RWEYEMANN, M.M. Bovine herpesviruses. Part I. Bovine herpesvirus 1. Veterinary Bulletin, v.47, n.5, p.317-343, 1977.

GOMES, L.I. et al. Detecção de herpesvírus bovino 5 (BoHV-5) em bovinos do Sudeste Brasileiro. Arquivo Brasileiro de Medicina Veterinária e Zootecnia, v.54, n.2, p.217-220, 2002.

GOUGH, A.; JAMES, A. Isolation of IBR virus from a heifer whit meningoencephalitis. Canadian Veterinary Journal, v.16, p.313-314, 1975.

HALFEN, D.C. et al. Imunogenicidade do herpesvírus bovino tipo 5 (BHV-5) em vacinas inativadas de diferentes formulações. Ciência Rural, v.30, n.5, p.851-856, 2000.

HOMAN, E.J.; EASTERDAY, B.C. Experimental latent and recrudescent bovine herpesvirus-1 infection in calves. American Journal Veterinary Research, v.44, n.2, p.309313, 1983.

JUBB, K.V.F.; HUXTABLE, C.R. Pathology of Domestic Animals. 4.ed. San Diego: Academic Press, 1993.

LIANG, X.; BABIUK, L.A.; ZAMB, T.J. An in vivo study of a glycoprotein gIII- negative bovine herpesvirus 1 (BHV1) mutant expressing b-galactosidase: evolution of the role of gIII virus infectivity and its use as a vector for mucosal immunization. Virology, v.189, p.629-639, 1992. 
METZLER, A.E.; SCHUDEL, A.A.; ENGELS, M. Bovine herpesvirus 1: molecular and antigenic characteristics of variant viruses isolated from calves with neurological disease. Archives of Virology, v.87, p.205217, 1986.

NAKAZATO, L. et al. Diferenciação anatomopatológica entre a meningoencefalite causada pelo herpesvírus bovino tipo 5 (BHV-5) e a poliencefalomalácia em bovinos no Mato Grosso do Sul. In: SIMPÓSIO INTERNACIONAL SOBRE HERPESVÍRUS BOVINO (TIPO 1 E 5), VÍRUS DA DIARRÉIA VIRAL BOVINA (BVDV), 1998, Santa Maria. Anais... Santa Maria: Universidade Federal de Santa Maria, 1998. p.151.

NAKAZATO, L.; LEMOS, L.; RIET-CORRÊA, F. Poliencefalomalácia em bovinos nos Estados de Mato Grosso do Sul e São Paulo. Pesquisa Veterinária Brasileira, v.20, n.3, p.119-125, 2000.

RADOSTITS, O.M.; BLOOD, D.C.; GAY, C.C. Veterinary Medicine. 8.ed. London: Baillière Tindall, 1994.

REED, D.E.; BICKNELLI, E.J.; BURY, R.J. Sistemic form of infectious bovine rhinotracheitis in young calves. Journal American Veterinary Medical Association, v.163, p.753-755, 1973.

RIET-CORRÊA, F. et al. Meningoencefalite e necrose do córtex cerebral em bovinos causadas por herpesvírus bovino-1. Pesquisa Veterinária Brasileira, v.9, n.1-2, p.13-16, 1989.

ROCK, D.L. The molecular bases of latent infections by alphaherpesviruses. Seminars in Virology, v.4, p.157-165, 1993.

ROEHE, P.M. et al. Diferenciação entre os vírus da rinotraqueíte infecciosa bovina (BHV-1) e vírus da encefalite bovina (BHV-5) com anticorpos monoclonais. Pesquisa Veterinária Brasileira, v.17, n.1, p.41-44, 1997.

ROEHE, P.M. et al. Situação do BHV-1 e BHV-5 no Brasil. In: SIMPÓSIO INTERNACIONAL SOBRE HERPESVIIRUS BOVINO (TIPO 1 E 5), VÍRUS DA DIARRÉIA VIRAL BOVINA (BVDV), 1998, Santa Maria. Anais... Santa Maria: Universidade Federal de Santa Maria, 1998. p.89-96.

ROIZMAN, B. et al. The family herpesviridae: An up date. Archives of Virology, v.28, n.1, p.1-7, 1992.
ROMERA, S. et al. Different vaccines against BHV-1: a long term evaluation of immune response induced in calves. In: SIMPÓSIO INTERNACIONAL SOBRE HERPESVÍRUS BOVINO (TIPO 1 E 5), VÍRUS DA DIARRÉIA VIRAL BOVINA (BVDV), 1998, Santa Maria. Anais... Santa Maria: Universidade Federal de Santa Maria, 1998. p.157.

ROS, C. et al. Improved detection of five related ruminant alphaherpesviruses by specific amplification of viral genomic sequences. Journal of Virological Methods, n.83, p.55-65, 1999.

SALVADOR, C.S. et al. Meningoencefalite em bovinos causada por herpesvírus bovino-5 no Mato Grosso do Sul e São Paulo. Pesquisa Veterinária Brasileira, v.18, n.2, p.76-83, 1998.

SCHUDEL, A.A. et al. Infections of calves whith antigenic variants of bovine herpesvirus 1 (BHV-1) and neurological disease. Journal of Veterinary Medicine B, v.33, p.303-310, 1986.

SCHWYZER, M.; ACKERMANN, M. Molecular Virology of ruminant herpesviruses. Veterinary Microbiology, v.53, p.17-29, 1996.

SILVA, A.M. et al. Infecção aguda e latente em ovinos inoculados com o herpesvírus bovino tipo 5 (HVB-5). In: SIMPÓSIO INTERNACIONAL SOBRE HERPESVÍRUS BOVINO (TIPO 1 E 5), VÍRUS DA DIARRÉIA VIRAL BOVINA (BVDV), 1998, Santa Maria. Anais... Santa Maria: Universidade Federal de Santa Maria, 1998. p.158.

SMITH, B.P. Large Animal Internal Medicine. 2.ed. London: C.V. Mosby, 1996.

SOUZA, V.F. et al. Caracterização de herpesvírus bovinos tipos 1 (BHV-1) e 5 (BHV-5) com anticorpos monoclonais. Pesquisa Veterinária Brasileira, v.22, n.1, p.13-18, 2002.

STRAUB, O.C. Problems concerning the taxonomy of the "moval type" bovine herpesvirus. Intervirology, v.28, n.1, p.1-7,1982.

STRAUB, O.C. Infectious bovine rhinotracheitis virus. In: DINTER, Z.; MORUN, B. Virus Infectious of Ruminants. Amsterdam: Elsevier Science Publishers, 1990. v.3, p.71-108.

STRAUB, O.C. BHV-1 Infectious: Relevance and spread in Europe. Compendium in immunology, Microbiology and Infectious Diseases, v.14, n.2, p.175-186, 1991. 
STUDDERT, M.J. Bovine encephalitis herpesvirus. Veterinary Record, v.125, p.584, 1989.

TEIXEIRA, M.F.B. et al. Avaliação de anticorpos contra herpesvírus bovinos tipos 1 (BHV-1) e 5 (BHV-5) por testes de soroneutralização. VI Virológica, 1997, Fortaleza, CE. Virology Reviews and Research, v.2, n.1-2, p.150, 1997.

VAN DRUNEN LITTEL-VAN DER HURK, S.; HUGHES, G.; BABIUK, L.A. The role of carbohydrate in the antigenic and immunogenic struture of bovine herpesvirus type 1 glicoproteins gI and gIV. Journal of General Virology, v.71, p.2053-2063, 1990.
VASCONCELOS, R.O.; VARASCHIN, M.S.; WAUTERS, F. Meningoencefalite bovina por herpesvírus. In: ENCONTRO NACIONAL DE PATOLOGIA VETERINÁRIA, 1993, Santa Maria, RS. Anais... Santa Maria, 1993. p.11.

WATT, J.A. et al. Infectious bovine rhinotracheitis encephalitis. Veterinary Record, v.108, p.63-64, 1981.

WIRTH, U.V. Comparasion of immediate-early transcripte among bovine herpesvirus type 1 and type 5 strains differing in neurovirulent potential. Virus Research, v.27, p.1-12, 1993. 